\section{Jose Luis Vázquez-Barquero}

Jose Luis Vázquez-Barquero is Professor of Psychiatry and Director of Psychiatry at the University of Santander, and Director of the Psychiatry Research Unit at Cantabria, Spain. He trained at the University of Santiago de Compostela at Pamplona and at the Department of Psychiatry at the University of Cardiff. His special interests include social, epidemiological and community psychiatry and the study of and intervention in the early phases of mental illness, in particular, psychosis.

\section{If you were not a psychiatrist, what} would you do?

I would have liked to have been a writer or an architect but I chose psychiatry, perhaps because it was close to my original interests in philosophy and sociology. Unfortunately, I do not expect to have enough lives to explore these other alternatives.

What has been the greatest impact of your profession on you personally? The development of a tolerant and understanding outlook on human nature and behaviour. It has also helped me to have a more reflective attitude in my relations with others.

\section{Do you feel stigmatised by your profession?}

have never felt stigmatised; on the contrary, I have always felt that other health professionals have respect and a certain degree of admiration for our profession.

Who was your most influential trainer, and why?

Professor Kenneth Rawnsley taught me a humanitarian and scientific attitude towards those with mental illness and how to work and collaborate productively within multidisciplinary teams. I developed an enquiring attitude to research and to clinical practice from Professor Michael Shepherd.

\section{What job gave you the most useful} training experience?

My first year of training with Professor José Soria in the Department of Psychiatry of Pamplona University where I learned phenomenology and the theoretical ideas of German psychiatry. Both have influenced my later work and interests.

Which book/text has influenced you most?

Many books have been influential in my professional life, among these I should

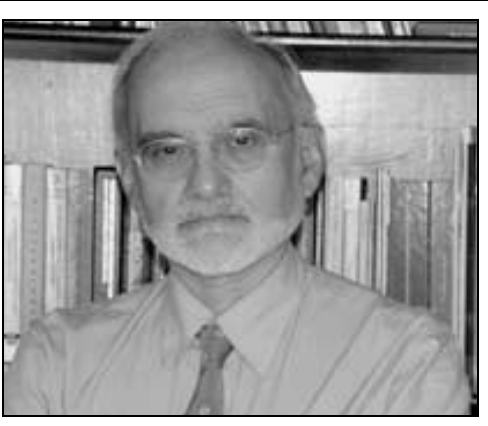

mention Karl Jaspers' General Psychopathology, Mental Illness in the Community by Goldberg and Husley, Institutionalism and Schizophrenia by Wing and Brown, Recovery from Schizophrenia by Warner and more recently The Recognition and Management of Early Psychosis by McGorry and Jackson

What part of your work gives you the most satisfaction?

Undoubtedly the opportunity to combine clinical practice with my research interests and with teaching.

\section{What do you least enjoy?}

Having to spend time explaining the needs of our psychiatric department to the never-ending procession of new managers.

\section{What is the most promising} opportunity facing the profession? The potential to identify biological and psychopathological markers of risk for the onset and course of psychiatric illnesses. This will allow early identification and management, thus improving the outcome and diminishing the associated stigma

\section{What is the greatest threat?}

The growing trends for managerial and bureaucratic over-regulation of clinical and research work.

What single change would substantially improve quality of care?

The achievement of parity of mental illness with medical diseases, both in terms of the allocation of resources and the disappearance of discrimination and stigmatisation.

Do you think psychiatry is brainless or mindless?

Neither. Psychiatry is, or should be, a balance between mind and brain which define the essence of being human.
How would you entice more medical students into the profession? By exploring with them the many intriguing and exciting questions which are still open in relation to the understanding, prevention and treatment of mental illness.

What is the most important advice you could offer to a new trainee? Try to keep an open mind without establishing value judgements about patients' behaviour. Understand that you, yourself are potentially the most powerful therapeutic tool you have. Maintain a balance between your clinical and research interests.

What are the main ethical problems that psychiatrists will face in the future?

Balancing the interests of patients, family and society with respect to disclosure of information in a world of increasingly open communication. Also, and not less important, how to define the limits of acceptable genetic manipulation in the context of mental illness.

What single change to mental health legislation would you like to see? A mechanism that would guarantee an optimal minimum level of resource allocation across the EU nations and harmonisation of mental health legislation in different EU countries.

What is the future for psychotherapy in psychiatry training and practice? There is growing evidence that the combination of certain forms of psychotherapy with pharmacological treatments is significantly more effective than each of these types of treatment in isolation and thus it is clear that in the future psychiatrists should be capable of delivering these two modalities of intervention. I firmly believe that the view that the practice of psychotherapy should be left to other mental health professionals is misguided.

What single area of psychiatric practice is most in need of development? The extension of the 'early phase of psychosis' paradigm to the rest of mental illness. This will lead to new conceptualisations of the origin, nature and psychopathological expression of the different diseases, new assessment instruments and novel interventions.

Dominic Fannon 